\title{
The Use of Food Coloring Dyes in Bacterial Staining
}

\author{
Rio Risandiansyah ${ }^{1 *}$, Arniyati Arniyati ${ }^{1}$, Nofie Irmalia Nurita ${ }^{1}$, Natasya Hana Gionika ${ }^{2}$ \\ ${ }^{1}$ Central Laboratory of Medical Research, Faculty of Medicine, University of Islam Malang, Indonesia \\ ${ }^{2}$ Study Program of Pharmacy, Faculty of Medicine, University of Islam Malang, Indonesia
}

\begin{abstract}
Staining creates a contrast between the cells and its surrounding, and enables the microscopic characteristics of bacterial cells to be easily visible and distinguished. However, staining often relies on dyes which are expensive, not readily available, or toxic. In this study, the use of food coloring dyes to stain bacteria was explored. We stained Grampositive bacteria (Bacillus sp. and Staphylococcus aureus) and Gram-negative bacteria (Escherichia coli) using several food coloring dyes of different colors, which were purchased locally. After slide fixation, the dye was flooded on the bacterial smear and air-dried for up to 30 minutes and observed by using microscope before and after washing with water. The results of this study show that prior to washing, most food coloring dyes were able to stain bacterial cells. However, after washing, only pink and purple food coloring dyes were retained, showing pink colored cells. We suspected that erythrosine was the agent responsible for this result, and was able to show similar characteristics with erythrosine alone. This study concludes that food coloring dyes containing erythrosine can be used to stain bacterial cells indiscriminately.
\end{abstract}

Keywords: Bacterial cell staining, erythrosine, food coloring dyes, resource-limited.

\section{INTRODUCTION}

Staining is a basic technique in microscopy, crucial in determining the basic morphological structure and characteristics to separate and identify one cell to another. Cell staining relies on specific dyes capable to bind to specific structures of a cell (such as nucleic acids or cytoplasm) and retains within these structures [1]. It creates a contrast between the cells and its surrounding and enables the cells to be visualized and characterized. Gram staining, in which its discovery is an important milestone in medical microbiology [2], for instance, a bacterial cell can be separated into Gram positive or negative based on the components of its cell wall and its ability to retain stain after alcoholic washing [3].

Cell staining is particularly useful in histology, pathology, and microbiology [4,5], and few studies exist which explores new staining method and techniques within the last decade $[6,7]$. However, the difficulty of the discovery of novel stains, such as in the case of the discovery of Gram staining, often relies on trial and error and has a degree of serendipity involved [3]. It is a common perception that diagnosis requires techniques with higher sensitivity and specificity, such as nucleic acid amplification techniques or fluorescent microscopy. However, even in these techniques, there is a demand for novel stains that are safer for the environment, less toxic,

\footnotetext{
* Correspondence address:

Rio Risandiansyah

Email : risandiansyah@gmail.com

Address : Faculty of Medicine, University of Islam Malang Jl. Mayjen Haryono No. 193 Malang 65144
}

readily available, and less expensive, yet having similar efficacy with current stains [8].

Staining techniques are important in the field of medical microbiology. Bacterial staining, usually Gram staining, is often used to guide therapy in patients with infections [9], and particularly considering increased antibiotic resistance [10]. Other stainings, such as simple staining and vital staining, may be used to rapidly detect the presence of bacteria or even pathogenic bacteria using a single stain method $[7,11,12]$. Point-of-care in rural or underdeveloped areas, however, provide logistical challenges in obtaining a Gram kit, or any other staining kits, and may be a barrier to the technique. Furthermore, some compounds used in several single staining procedures are considered to be toxic to humans and the environment and, in the case of crystal violet, may even be considered to be carcinogenic $[13,14]$.

Food coloring, unlike chemical staining kits, are often easier to find as well as being less toxic to human health, although some has reported the compounds contained in food coloring to be unsafe for consumption if taken chronically [15]. Food coloring often contains chemicals, which are also known to be bacterial stains, such as erythrosine [16], brilliant blue FCF [17], and sunset yellow [7]. However, previous research has used those substances in controlled concentrations, and not when they are packaged in a food coloring product.

In this paper, we explore the use of foodgrade food coloring to stain Gram-positive and 
Gram-negative bacteria. We then evaluate the ability after each stain to evaluate the basic microscopic characteristic of each bacteria, whether the stain can stain bacteria with different characteristics, and whether the stain is retained after washing. On successful stains, a food-grade pure compound was used and tested for the concentration with the best bacterial visualization.

\section{MATERIAL AND METHOD}

\section{Bacteria preparation}

Bacteria (Bacillus sp., Escherichia coli, and Staphylococcus aureus) were obtained from the Laboratory of Microbiology, Department of Biology, University of Brawijaya, Malang. Prior to staining, bacteria were subcultured in nutrient agar plates (Merck, peptone 5 g. $\mathrm{L}^{-1}$, Meat extract 3 g. $\mathrm{L}^{-1}$, and Agar $12 \mathrm{~g} . \mathrm{L}^{-1}$ ) and incubated at $37^{\circ} \mathrm{C}$ for at least 20 hours. The bacteria stained in this study were a Gram-positive bacillus (Bacillus sp.), a Gram-negative bacillus (Escherichia coli), and a Gram-positive coccus (Staphylococcus aureus).

\section{Bacteria fixing for staining}

Prior to any staining method, bacteria were fixed on a glass microscope slide by the following method, based on established literature. A sterile loop of bacteria from the aforementioned plates was mixed with a small drop of normal saline from a glass pipette on a glass slide under a biosafety cabinet. The slides were left to dry inside the biosafety cabinet for approximately 10 minutes, and fixated by passing the slides through an open flame. These slides were then used directly for staining. All staining was performed on a staining tray.

\section{Staining method using water-based food coloring}

Food coloring was purchased from a local bakery material store. The brand of the food color was chosen randomly, however, the color chosen was determined by its constituent. For this study, several food colorings were used in the initial food stain. A dark red food color (HakikiTM; ingredients: Sorbitol, Ponceau 4R Cl No. 16255, Carmoisine $\mathrm{Cl}$ No. 14720, and Tatrazine Cl No. 19140), blue food color (R\&WTM; ingredients: Sorbitol, Brilliant Blue $\mathrm{Cl}$ No. 42090), pink food color (R\&WTM, ingredients: Sorbitol, Erythrosine Cl No. 45430, Carmoisine $\mathrm{Cl}$ No. 14720), and purple food color (HAKIKITM; ingredients: Erythrosine $\mathrm{Cl}$ No. 45430, Brilliant Blue No. 42090) were tested in this study. The bacterial smear on slides was flooded with the food coloring and left for 1 minute, and drained without washing. The slides were then left at least 30 minutes before observation under a microscope. After the images were taken, the slides were washed under running water, left to dry for 10 - 30 minutes, and the images were taken again using the same method.

\section{Staining method using Erythrosine}

Erythrosine was purchased from a local chemical store and was oil-based food grade erythrosine (PT. Subur Kimia Jaya). The erythrosine obtained was in the form of a maroon-colored powder. Erythrosine was mixed with distilled water at $1 \mathrm{mg} \cdot \mathrm{mL}^{-1}, 0.1 \mathrm{mg} \cdot \mathrm{mL}^{-1}$, $0.01 \mathrm{mg} \cdot \mathrm{mL}^{-1}$, and $0.001 \mathrm{mg} \cdot \mathrm{mL}^{-1}$ and prepared at a volume of approximately $25 \mathrm{~mL}$. The staining method was similar to the previous method, whereas the slides were flooded with the stain, left for 1 minute, drained without washing, and left for an additional 30 minutes to 1 hour before observation by a microscope.

\section{Microscope image capturing}

A trinocular microscope was used to obtain images of the preparation with 1000x magnification, medium light, the diaphragm set accordingly, and using a drop of immersion oil. After focusing, the images were obtained using the ocular camera and cropped for similar dimensions.

\section{RESULT AND DISCUSSION}

Unwashed single staining of bacteria using various food coloring dyes

Samples of bacteria obtained from nutrient agar plates were fixated and single stained, as described in the methodology section. Based on the images in Fig. 1, the microscopic characteristics of the bacterial cells were mostly clearly observable after food coloring application. Red food coloring resulted in outlining the cell borders, with clear and colorless area internal to the bacterial cells on all Gram-positive and Gramnegative bacteria, as with purple food coloring in Bacillus sp. bacteria. However, in several stains, the cells appear more visible, having a darker hue, such as observed in blue food color, pink food color in all bacterial Gram types, and purple food color in E. coli. The results of purple coloring in $S$. aureus were not visible, resulting in no staining patterns that were easily observable in Gram-positive or Gram-negative bacteria. However, bacilli bacteria were easier to observe and differentiate compared to cocci bacteria. 


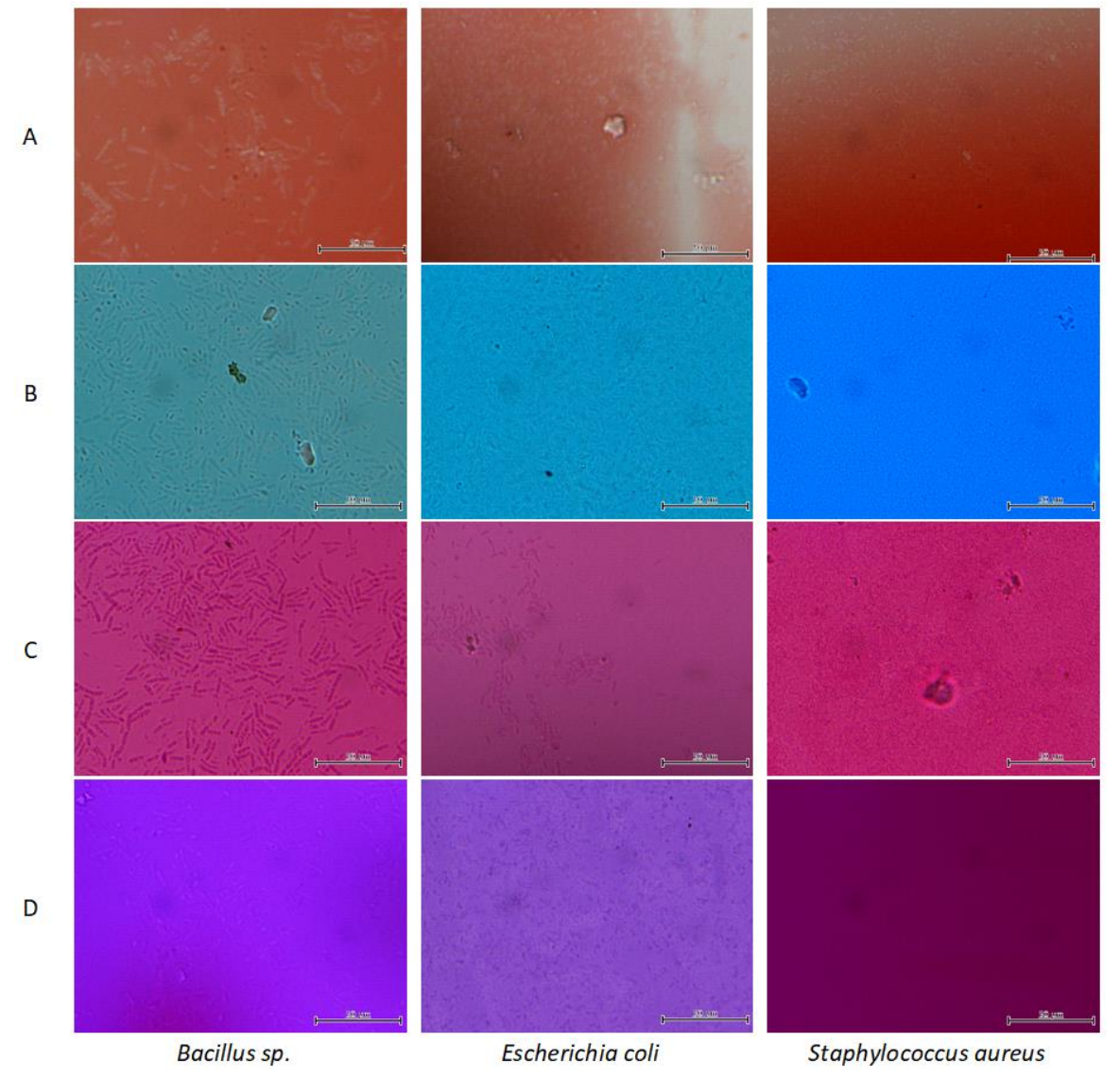

Figure 1. Cell images of various Gram positive and negative bacteria stained using various water-based food coloring without washing. The cells were stained using A. red food coloring, B. blue food coloring, C. pink food coloring, and D. purple food coloring. The basic cell morphology was clearly observable using these staining methods, however, no differentiation in Gram type was possible. The scale line was $50 \mu \mathrm{m}$.

\begin{abstract}
Washed single staining of bacteria using various food coloring dyes

During washing, it was observed that the food color was washable using running water. However, observation under a microscope revealed that each food coloring was retained differently (Fig. 2). As shown in the images in Figure 2, food coloring was retained differently after washing. Red food coloring was not retained or faintly retained in Bacillus $s p$. and $S$. aureus, but was more clearly retained in E. coli.

Other food colorings were retained in most bacterial cells, regardless of their Gram type, with the most clearly retained food coloring in pink food coloring and purple food coloring. Furthermore, cell morphology and a staphylo type configuration were observable under pink food coloring staining in S. aureus.
\end{abstract}

\section{Staining of bacteria using erythrosine with various concentrations}

Cell visualization after staining with erythrosine was shown in Figure 3. Erythrosine used in this study was found to have low solubility with water, resulting in patches of stain debris across all bacterial slides. Erythrosine was found to stain bacteria regardless of Gram type with varying degrees depending on the concentration used. However, the images were accompanied by an amount of staining debris the higher the concentration of the erythrosine used.

At the lowest concentration of erythrosine, the cells, in particular $S$. aureus, were only faintly stained. However, it also had a relatively lower amount of staining debris. S. aureus was only clearly visible on the highest concentration of erythrosine. On the other hand, Bacillus $s p$. And $E$. coli was visible using erythrosine even up to a concentration as low as $0.01 \mathrm{mg} \cdot \mathrm{mL}^{-1}$. 


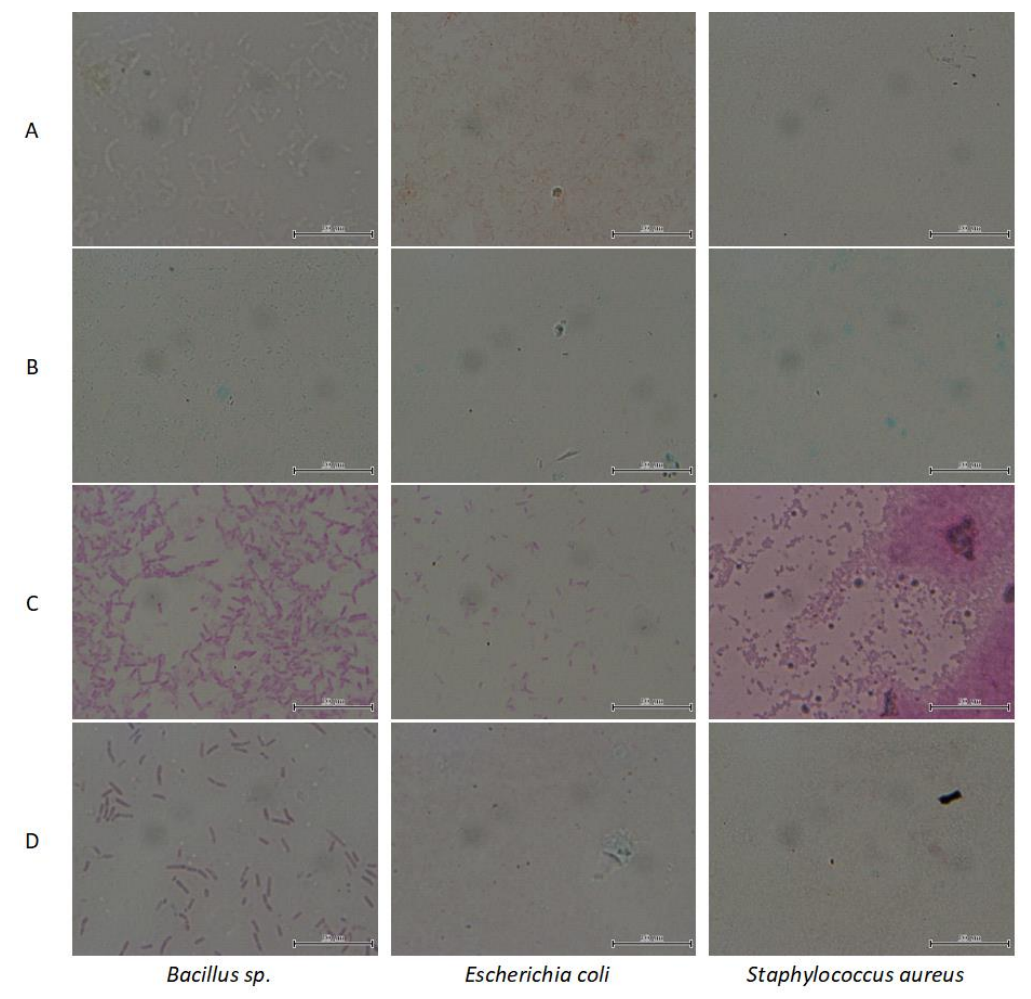

Figure 2. Cell images of various Gram positive and negative bacteria stained using various water-based food coloring and washed after staining. The cells were stained using A. red food coloring, B. blue food coloring, C. pink food coloring, and D. purple food coloring. Stains were retained differently between each bacterial type, but no differences were observed within different Gram types. The scale line was $50 \mu \mathrm{m}$.

A

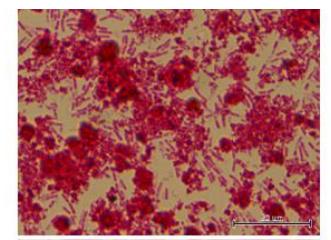

B

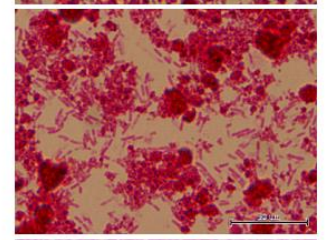

C

D
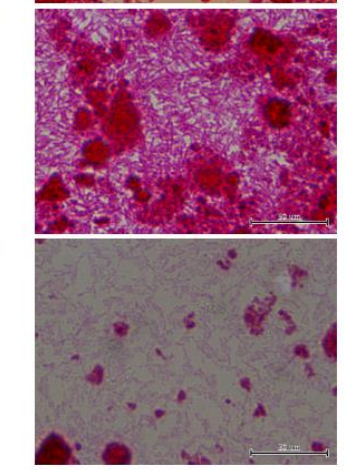

Bacillus sp.
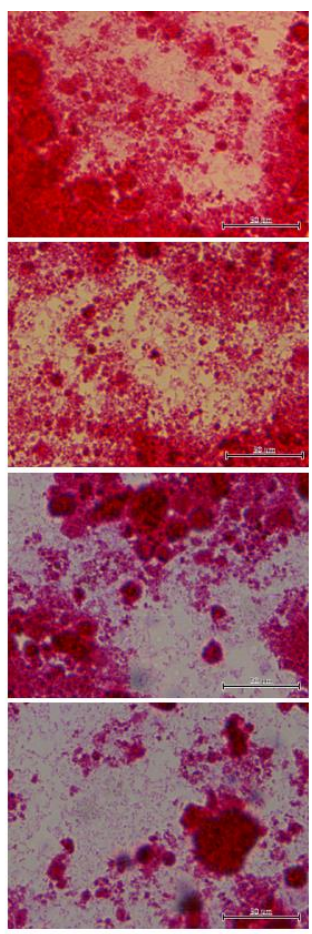

Escherichia coli
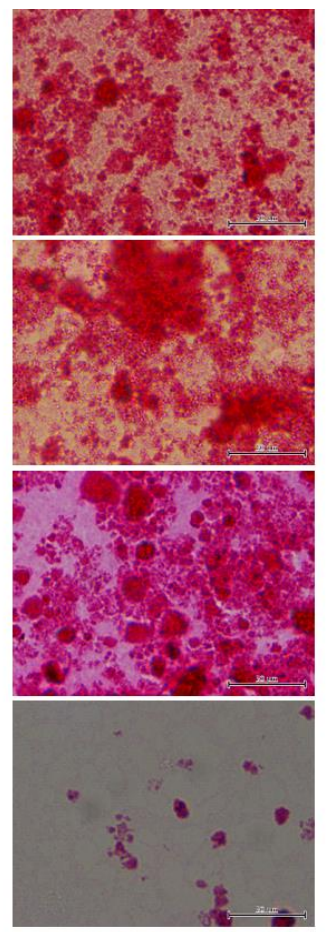

Staphylococcus aureus

Figure 3. Cell images of Gram positive and negative bacteria using various concentrations of erythrosine. The cells were stained using erythrosine at A. $1 \mathrm{mg} \cdot \mathrm{mL}^{-1}$, B. $0.1 \mathrm{mg} \cdot \mathrm{mL}^{-1}$, C. $0.01 \mathrm{mg} \cdot \mathrm{mL}^{-1}$, and D. $0.001 \mathrm{mg} / \mathrm{ml}$. erythrosine was found to be able to stain all cells, regardless of Gram type. The scale line was $50 \mu \mathrm{m}$. 


\section{DISCUSSION}

Bacterial staining has many applications in the medical field or in even microbiology science, either to show the cell shape and formation, to pinpoint specific structures, and even used as a golden standard for some the determination of pathogens. For example, Gram stains can pinpoint the basic microscopic characteristics of a cause of an infectious disease. Positive results in an acid-fast stain, using a red color carbolfuchsin, can indicate the presence of acidresistant bacteria having a mycolic cell wall. Special characteristics of the bacteria can be stained using negative staining, capsule staining, spore staining, flagellar staining, as well as other methods.

Modification of Gram-stain is rarely done, but discoveries for alternatives have been done in several recent researchers by using different dyes or stains, which result in higher contrast [6]. In other cases, novel staining methods were developed in dentistry to detect the presence of oral biofilm in the teeth and gums $[10,18]$. However, the experiments tend to use pure compounds and do not generally use foodcoloring dyes directly.

In this experiment, food-coloring dyes used contain a mixture of sorbitol and one or two coloring agents. It was observed that staining was retained after washing when using dyes containing erythrosine. Previous use of erythrosine found it to be taken up and able to inhibit Streptococcus mutans biofilm and therefore used as photodynamic therapy (PDT) for gingivitis [19]. Erythrosine was already classified as a biological stain [20], and recently, erythrosine has been shown to be able to stain several Gram-positive and Gram-negative bacteria indiscriminately, including Bacillus cereus, Escherichia coli, Klebsiella pneumoniae, Pseudomonas flourescens, Serratia marcesans, Streptomyces albus, Streptococcus mutans, Proteus mirabilis, Staphylococcus aureus, and Enterococcus faecalis [16].

This study also showed the efficacy of several different food coloring in staining bacteria. Our findings suggest that pink and purple food coloring was found to not only be taken by the bacterial cells, thus enabling the cells to be visible, because the stains were retained after washing. A common ingredient in both the pink and purple food coloring tested was erythrosine. Thus, we then tested using a purer form of erythrosine in a further test. This result supports other studies $[15,16]$ and can report that erythrosine can also, in fact, stain the bacterial cells, albeit non-discriminatory. Erythrosine is reported as a membrane-impermeable stain and only taken by non-viable cells, such as after heat treatment [21]. As heat fixation was employed in this method, a similar process could explain how the food-colors containing erythrosine was able to stain the bacterial cells.

The advantages of using food coloring as a way to stain bacteria is that food coloring is relatively less toxic compared to several compounds used in conventional stains. Crystal violet, a component in Gram staining and also can be used in simple staining procedures [11], is reported to be mutagenic, a potent carcinogen and potent clastogenic, as well as persisting in the environment for a long period [13]. This study shows the possibility of unconventional methods to be used in the development of bacterial staining methodology.

\section{CONCLUSION}

Food coloring containing erythrosine can be used to stain bacterial cells indiscriminately.

\section{ACKNOWLEDGEMENT}

We would like to thank the Medical Faculty, University of Islam Malang, for providing us with the equipment required to do the experimentation.

\section{REFERENCES}

[1] Baskin, D. G. 2015. A historical perspective on the identification of cell types in pancreatic islets of langerhans by staining and histochemical techniques. J. Histochem Cytochem. 63(8). 543-58. doi: 10.1369/ 0022155415589119.

[2] Alturkistani, H.A., F.M. Tashkandi, Z.M. Mohammedsaleh. 2015. Histological stains: a literature review and case study. Glob J. Health Sci. 8(3). 72.

[3] Bartholomew, J.W., T. Mittwer. 1952. The Gram stain. Microbiol. Mol. Biol. Rev. 16(1). 1-29.

[4] Braak, H., S. Feldengut, J. Kassubek, D. Yilmazer-Hanke, K. Del Tredici. 2018. Two histological methods for recognition and study of cortical microinfarcts in thick sections. Eur J. Histochem. 62(4). 313-317.

[5] Ergün, E., L. Ergün, R.N. Asti, A. Kürüm. 2003. Light and electron microscopic morphology of Paneth cells in the sheep small intestine. Rev. Med. Vet. (Toulouse) 154(5). 351-355.

[6] Salleh, F.M., A.M. Al-Mekhlafi, A. Nordin, M. 
Yasin 'Azlin, H.M. Al-Mekhlafi, N. Moktar. 2011. Evaluation of gram-chromotrope kinyoun staining technique: Its effectiveness in detecting microsporidial spores in fecal specimens. Diagn. Microbiol. Infect. Dis. 69(1). 82-85.

[7] Gao, P., C. Sun, Y. Li, X. Zou, X. Wu, Y. Ling, et al. 2011. Vital staining of bacteria by sunset yellow pigment. Polish J. Microbiol. 66(1). 113-117.

[8] Kim, S.I, H.J. Kim, H.J. Lee, K. Lee, D. Hong, H. Lim, et al. 2016. Application of a nonhazardous vital dye for cell counting with automated cell counters. Anal Biochem. 492(3). 8-12. doi: 10.1016/j.ab.2015.09.010

[9] Tokuda, Y., M. Koizumi, G.H. Stein, R.B. Birrer. 2009. Identifying Low-risk patients for bacterial meningitis in adult patients with acute meningitis. Intern. Med. 48(7). 537-543.

[10] Becerra, S.C., D.C. Roy, C.J. Sanchez, R.J. Christy, D.M. Burmeister. 2016. An optimized staining technique for the detection of Gram positive and Gram negative bacteria within tissue. BMC Res Notes 9(1). 216. doi: 10.1186/s13104-0161902-0

[11] Moyes, R.B., J. Reynolds, D.P. Breakwell. 2009. Preliminary staining of bacteria: simple stains. Curr. Protoc. Microbiol. Appendix 3: Appendix 3E.

[12] Cluss, R.G., N.L. Somerson. 1984. Simple staining procedure permits rapid counting of mycoplasma colonies. J. Clin. Microbiol. 19(4). 543-545.

[13] Mani, S., R.N. Bharagava. 2016. Exposure to crystal violet, its toxic, genotoxic and carcinogenic effects on environment and its degradation and detoxification for environmental safety. In: Reviews of environmental contamination and toxicology. United States. 71-104.

[14] Gillman, P.K. 2010. Methylene blue and serotonin toxicity: definite causal link. Psychosomatics. 51. 448-449.

[15] Merinas-Amo, R., M. Martínez-Jurado, S. Jurado-Güeto, Á. Alonso-Moraga, T. Merinas-Amo. 2019. Biological effects of food coloring in in vivo and in vitro model systems. Foods. 8(5). 176.

[16] Franke, J.D., A.L. Braverman, A.M. Cunningham, E.E. Eberhard, G.A. Perry. 2020. Erythrosin B: a versatile colorimetric and fluorescent vital dye for bacteria. Biotechniques. 68(1). 7-13. doi: 10.2144/ btn-2019-0066

[17] Chau, H., Y. Goh, B. Si, V. Vujanovic. 2011. An innovative brilliant blue FCF method for fluorescent staining of fungi and bacteria. Biotech. Histochem. 86(4). 280-287. doi: 10.3109/10520295.2010.492733

[18] Ishiyama, K., K. Nakamura, T. Kanno, Y. Niwano. 2016. Bactericidal action of Photodynamic Antimicrobial Chemotherapy (PACT) with photosensitizers used as plaque-disclosing agents against experimental biofilm. Biocontrol Sci. 21(3). 187-191.

[19] Wood, S., D. Metcalf, D. Devine, C. Robinson. 2006. Erythrosine is a potential photosensitizer for the photodynamic therapy of oral plaque biofilms. J. Antimicrob. Chemother. 57(4). 680-684.

[20] Penney, D.P., J.M. Powers, M. Frank, C. Willis, C. Churukian. 2002. Analysis and testing of biological stains-- The Biological Stain Commission Procedures. Biotech. Histochem. 77(5-6). 237-275. doi: 10.1080/ bih.77.5-6.237.275

[21] Krause, A.W., W.W. Carley, W.W. Webb. 1984. Fluorescent erythrosin B is preferable to trypan blue as a vital exclusion dye for mammalian cells in monolayer culture. J. Histochem. Cytochem. 32(10). 1084-1090. 